\title{
"External environmental considerations in the planning of strategies of car dealerships"
}

\begin{tabular}{|c|c|c|}
\hline AUTHORS & \multicolumn{2}{|l|}{$\begin{array}{l}\text { Makgopa S. Sipho } \\
\text { Theron Daniel }\end{array}$} \\
\hline ARTICLE INFO & \multicolumn{2}{|c|}{$\begin{array}{l}\text { Makgopa S. Sipho and Theron Daniel (2017). External environmental } \\
\text { considerations in the planning of strategies of car dealerships. Environmental } \\
\text { Economics, 8(1), 83-92. doi:10.21511/ee.08(1).2017.09 }\end{array}$} \\
\hline DOI & \multicolumn{2}{|c|}{ http://dx.doi.org/10.21511/ee.08(1).2017.09 } \\
\hline RELEASED ON & \multicolumn{2}{|l|}{ Wednesday, 12 April 2017} \\
\hline & \multicolumn{2}{|l|}{$(c c)$ EY-NC } \\
\hline LICENSE & \multicolumn{2}{|c|}{$\begin{array}{l}\text { This work is licensed under a Creative Commons Attribution-NonCommercial } 4.0 \\
\text { International License }\end{array}$} \\
\hline JOURNAL & \multicolumn{2}{|l|}{ "Environmental Economics" } \\
\hline ISSN PRINT & \multicolumn{2}{|l|}{$1998-6041$} \\
\hline ISSN ONLINE & \multicolumn{2}{|l|}{$1998-605 X$} \\
\hline PUBLISHER & \multicolumn{2}{|c|}{ LLC "Consulting Publishing Company "Business Perspectives" } \\
\hline FOUNDER & \multicolumn{2}{|c|}{ LLC "Consulting Publishing Company "Business Perspectives" } \\
\hline \multirow[b]{2}{*}{ NUMBER OF REFERENCES } & & ニシ: \\
\hline & NUMBER OF FIGURES & NUMBER OF TABLES \\
\hline 20 & 0 & 0 \\
\hline
\end{tabular}

(c) The author(s) 2023. This publication is an open access article. 
Makgopa S. Sipho (South Africa), Theron Daniel (South Africa)

\title{
External environmental considerations in the planning of strategies of car dealerships
}

\begin{abstract}
This paper focuses on the external environmental factors that have an impact on the planning of organizational strategies from car dealerships perspective. The paper argues, that the organization`s failure to consider and analyze external environmental factors could render strategies, particularly, marketing communication strategies and campaigns ineffective. It is pertinent to note that the external environmental factors of consideration during the environmental analysis may vary amongst different industries and sectors of the economy. In effective planning of strategies organizations, including car dealerships, in theory are expected to conduct external environmental analysis with more emphasis on market and macro-environments. The purpose of this paper is to test this theory by exploring on market and macro environmental factors that are of consideration in planning marketing communication strategies and campaigns of car dealerships in practice. In order to achieve the purpose of the paper, a qualitative research approach using semi-structured in-depth interviews with marketing personnel of different car dealerships in Gauteng, South Africa was implemented. The paper utilizes a qualitative content analysis in analyzing primary data using Atlas ti version 7 computer software. The results revealed that the economic, season factors and technological advances that might lead to environmental conservation and the target audiences serve as key factors of consideration in the external environment during the planning of marketing communication strategies and campaigns. The results of this paper can be used as a basis for recommendations to stakeholders in the motor vehicle industry. Finally, future research directions are provided.
\end{abstract}

Keywords: external environment, market environment, economic environment, social environment, technological environment, seasonal factors, strategy, marketing communication strategy, qualitative research.

JEL Classification: Q55, M31.

\section{Introduction}

Today's external environment is very much dynamic characterized by quick changes, particularly, technological changes and a need for organizations to exercise environmental consciousness in planning their strategic strategies and activities. Marketing communication as one of organizational activity is characterized as being the most complex, considering new technological changes, changes consumers media preferences, and pressure to conserve environment from the government taking place in the organizations' external environment. In recent years this complexity has been made even more prevalent by the emergence of new digital media types. These new media types present new opportunities for organizations and marketers of organizations, but also bring great difficulty to managerial decision making. To highlight just a few of the benefits of marketing communications, marketers can choose to

(c) Makgopa S. Sipho, Theron Daniel, 2017.

Makgopa S. Sipho, M.Phil., M.Com. and Ph.D. Candidate, General Management Lecturer, University of South Africa, South Africa.

Theron Daniel, MBA and Ph.D. Candidate, Department of Marketing and Retail Management, University of South Africa, South Africa.

This is an Open Access article, distributed under the terms of the Creative Commons Attribution-NonCommercial 4.0 International license, which permits re-use, distribution, and reproduction, provided the materials aren't used for commercial purposes and the original work is properly cited. do some or all of the following with their brands. Recently, organizations can reach consumers through mass or targeted advertisements on social media networks, banner or display advertisements on websites; and paid search engine. Internet applications present customers with opportunities to create relationships amongst themselves regardless of geographic borders constraints of or time zones (Zhou, 2011). Internet communication networks with larger member bases are appropriate channels through which organizations can promote their products or service offerings in order to shape brand preference, timely e-mails can be send to consumers to provide detailed content about organizations' service offerings. Organizations can drive shortterm sales by offering sales promotions through tweets, and text messages. And to reinforce longterm brand loyalty, organizations can create internet brand followers using self-created or third-party social media. Taking into account various new communication media platforms available to organizations, Batra and Keller (2016) postulate that organizations struggle to make effective marketing communication decisions due to continuous changes in the external environment. Therefore, it becomes imperative to explore the external factors of consideration in planning of marketing communication strategies and campaigns, in the context of car dealerships.

The next section briefly states the purpose of this paper. 


\section{The purpose of the study}

The purpose of this research was to explore the external environmental considerations, particularly, market and macro-environmental factors of consideration by car dealerships in planning marketing communication strategies and campaigns in a real life scenario. To address this research purpose requires theoretical background on external environmental factors considered in planning marketing communication strategies and campaigns, as well as literature review of previous studies on marketing communication.

\section{Theoretical background and literature review}

2.1. Macro-environment. In performing external environmental analyzis, the managers of organizations analyze market and macroenvironment, in which the organizations operate. The macro-environment consists of variables beyond the control of the organization's management (Van Schie, 2012). Varadarajan (2011) depicts that the macro-environment consists of the following sub-environments, namely, the political/legal environment, economic environment, social environment, technological environment, physical environment, and international environment. These sub-environments have an indirect influence on the organization's marketing strategy and its implementation based on the opportunities and threats these sub-environments present to the organization. Caemmerer (2009) suggests that environmental analyzis represents the first step in the planning and implementation of marketing communication by organizations, including those operating in the motor industry. This implies that the dealerships need to conduct an environmental analyzis in order to understand its position in the market, as well as its competitors' marketing communications. In addition, during environmental analyzis, the organization's internal resources, products or services, what competitors are doing and the general marketing communication trends in the industry must be investigated. In addition, surveys are conducted to track, for example, consumers' attitudes towards car brands to establish, what they perceive about these vehicle brands.

On the same token, macro-environmental analyzis as a part of external environmental analyzis should highlight favorable marketing communication opportunities for the organization (Caemmerer, 2009). The macro-environment consists of variables beyond the control of the organization's management (Van Schie, 2012). Varadarajan (2011) pointed that the macro-environment consists of the following sub-environments, namely, the political/ legal environment, economic environment, social environment, technological environment, physical environment, and international environment. These sub-environments have an indirect influence on the organization's marketing strategy and its implementation based on the opportunities and threats these sub-environments present to the organization. The sub-environments in the macroenvironment which present possible opportunities or threats or might impact on the marketing strategy and marketing communication strategy that forms the focus of this study are explored below.

2.1.1. The legislative/ political environment. The political environment defines the monetary and legislative policies of the country in which an organization operates (De Beer, 2012). It includes policies, laws and regulations of the government that influence the business activities (including marketing activities) of the organization (Lamprecht, 2009). Government, as a regulatory body, affects the business environment in which organizations operate, for example, through tax laws, labor laws, competition law, and so on. These laws may present opportunities or threats to organizations such as dealerships.

2.1.2. The economic environment. The economic environment includes external variables such as interest rates, inflation rates, level of economic growth, currency exchange rates, and fiscal and monetary policies (Bosdriesz, Witvliet, Visscher, and Kunst, 2012). Rollins, Nickell and Ennis (2014) indicate that an economic recession can severely affect the marketing performance and survival of organizations. The authors mentioned above highlight that during an economic recession, organizations alter their marketing strategies by either cutting marketing or $R \& D$ budgets, or investing in more marketing and R\&D. This argument is also backed by Cheong, Kim and Kim (2013), emphasizing that during an economic recession, retail sales are slow, and advertising budgets (which is part of the marketing communications budget) are often reduced, as organizations face severe pressure to cut back on marketing investments. This implies that organizations, such as dealerships should analyze the economic situation in the business environment, where they operate in order to understand if the current economic environment presents opportunities or may pose threats. 
2.1.3. The technological environment. The changes in the technological environment may present threats to the organization, because the cost of acquiring new technologies may significantly increase the capital costs of the organization, which, in turn, might affect the marketing budgets. On the other hand, these changes in technology may present opportunities to dealerships. For example, internet and mobile phones as contemporary media platforms can be utilized by marketers to convey marketing messages and allow customers to book for test drives online. The internet as an example of a technological force has proved to be an inexpensive way to interact with customers (Kiran, 2012). Kiran (2012) points out that the internet allows customers to search, view and buy products and services without necessarily having to personally visit the service providers.

Online social networking technologies, such as Facebook and Myspace are increasingly being used by organizations to generate more direct sales, and to attract and connect with customers more cheaply, than traditional marketing communication channels such as television, radio and newspapers (Mangold and Faulds, 2009). Caluschi (2013) points out that the motor industry is quick in adopting the new communication channels and trends, and tests them as part of their marketing communication mix.

2.1.4. The social environment. The social environment includes the values, beliefs, attitudes, opinions, and lifestyles of stakeholders outside the organization (Bosdriesz et al., 2012). In analyzing the social environment, a marketer needs to consider the factors associated with demographic and cultural forces with regard to the impact these factors may have on organization's marketing strategy. The analyzis of demographic factors includes the study of the human population regarding size, geographic distribution, age, education levels and income distribution (Bosdriesz et al., 2012). The social environment influences customers' buying behavior and product selections, and therefore, also the marketing strategy the organization should develop. Lamprecht (2009) points out that there are differences in literacy and consumer skills, as a result of a country's educational system, influence what kinds of adaptation in products and in marketing communications are necessary. Therefore, it is necessary for marketers to consider social factors that may impact on the marketing communication strategies of organizations.
2.1.5. The physical environment. The physical environment consists of the environment, from which the organizations access raw materials, and other natural resources. A country's natural resources are one indicator of its economic potential and raw material availability, while its topography helps determine the physical distribution and market accessibility (Lamprecht, 2009). These natural resources include the land and physical space on which organizations, such as dealerships, premises are built. The availability or the shortage of raw materials influence the marketing activities of an organization, for example, a shortage of available space on which to build a dealership may affect the marketing activities of the organization, as the dealership might not have sufficient space to accommodate its marketing staff and its stock.

De Craecker and De Wulf (2009) pointed out that the marketing communication in the motor industry usually goes side-by-side with the use of materials, which can even be considered as waste of resources, on some occasions. However, new communication elements and practices can be used to conserve resources, such as e-mail instead of postal mail, the use of recycled materials, if printing is really necessary, and more efficient processes like waterless printing in an attempt to conserve the environment.

2.2. Market environmental factors. Marketenvironmental analyzis as a part of situation analyzis should highlight favorable marketing communication opportunities for the organization (Caemmerer, 2009). Kliatchko (2009) emphasized that the marketing communication strategy should be congruent to the marketing strategy, which is derived from the overall business strategy. This implies that organizations, such as dealerships may use the SWOT analyzis model, as explained in the preceding section, when developing marketing communication strategies, in the same way as when developing the organization's overall business strategy and marketing strategy. In addition, in conducting an external environmental analyzis, organizations should identify their competitors ( $\mathrm{Wu}$ and Olk, 2014). This implies that the marketers of dealerships should identify their competitors' marketing communication activities, including the media channels and services they offer; placing more emphasiz on the competitors' marketing communication initiatives with the intention of developing distinctive marketing strategies.

The next section provides literature review of previous studies on marketing communication strategies and campaigns. 


\section{Literature review of previous studies}

Many studies indicated that organizations can benefit from these new platforms, as these platforms present opportunities through two-way online interactions (Fulgoni and Lipsman, 2014; Mangold and Faulds, 2009). In addition, these new platforms can be used, because they are considered to be convenient and cost-effective (Kirtiş and Karahan, 2011). Kirtiş and Karahan (2011) investigated whether firms spend less money via social media to realise their marketing strategies comparing with traditional media, as well as the importance of social media for the marketing area, the results of this study uncovered that the emergence of new media like online search and display advertising, video games, online user generated contents and word of mouth marketing mean both the advantage and the disadvantage for the firms. In the other study, Thomas (2010) pointed that social media is "CRM for millennia" but not a just simple marketing tool and its form may be different in the future, but it's not going away. According to Thomas (2010) organizations using social media point out that the more firms network, the more successful they become on the long-run benefits due to gaining from multiplicative effect of it.

Other previous studies investigated the relationship between advertising and business performance of organizations (Crespo-Cuaresma, 2012; Singh, Sharma and Mahendru, 2011). Crespo-Cuaresma (2012) investigated the relationship between advertising spending and sales performance in Germany within premium segment. The findings of this study uncovered that an increase in advertising expenditure resulted in high sales returns. Singh, Sharma, and Mahendru (2011) used quantitative approach in Indian organizations to investigate the cause and effect relationship between advertisement spending and sales, and the findings demonstrated that there is a positive relationship between advertising spending and sales. In another study by Buil, de Chernatony and Martínez (2013) the role of advertising as marketing communications tool in building brand was explored, and the findings revealed that although advertising contributes towards building brand knowledge, it has led to huge levels of marketing communication expenditure. The preceding studies have mainly focused on the relationship and causal effect between advertising spending and its efficiency in achieving high business performance rather than external environmental factors that impact on the planning of strategies. This study aimed to fill this gap in literature by focusing on these external environmental factors of consideration in planning marketing communication strategies and campaigns of car dealerships from South African context.

The next section provides the contribution of this study.

\section{Contributions of the study}

In reviewing the secondary research available, it is clear that the external environmental analyzis in the planning of marketing communication strategies and campaigns is not widely covered in literature, specifically in the car retail sector. This study contributes to literature on the topic by highlighting external environmental factors of consideration during the planning stage of marketing communication strategies and campaigns. This study further benefits car dealerships by revealing key environmental factors, specifically, market and macro-environmental factors, including new technological considerations that contribute towards environmental conservation by pin pointing increasing adoption of internet usage within car retail sector in an attempt to conserve resources and environment. Future research directions are provided in this study.

The next section provides the research methodology followed to accomplish the research purpose of this study.

\section{Research methodology}

An exploratory qualitative approach using semistructured in-depth interviews was followed in order to achieve the research objective. An exploratory research design is considered appropriate, when the researcher requires in-depth information concerning a particular problem, or a phenomenon (Malhotra, 2010). A qualitative research approach was selected as an appropriate research approach, as it allowed participants to share their opinions and experiences regarding the external factors considered in planning marketing communication strategies of car dealerships. A purposive sampling method was used in the current study, this sampling method requires that participants be chosen considering some defining characteristics that make them the holders of the data needed for the study (Tustin, Ligthelm, Martins, and Van Wyk, 2005). The target population in the current study was the car dealerships operating in Gauteng province, South Africa. Marketing executives and senior sales personnel of dealerships were selected as the unit of analyzis taking into account their involved in planning of marketing communication strategies and campaigns of car dealerships. Retail Motor Industry (RMI) member list was used as a sample frame in the current study as it contains the contact details of 
accredited dealerships operating in South Africa. The researcher used the e-mail addresses and telephone numbers, obtained from RMI member list to contact car dealerships to get contact details of marketing personnel and senior sales personnel (involved in planning of marketing communication strategies and campaigns). A content analyzis was used to analyze the interview transcripts with the aid of Atlas ti version 7 computer software to capture quotations and generate themes in line with research purpose of the current study. In following a qualitative research approach ethical considerations were observed with more emphasiz on confidentiality, reliability and credibility during participants' recruitment, data collection, data analyzis, and reporting.

The next section presents the findings of the current study.

\section{Findings}

The following variables of the external environment analyzis were found to be of consideration in planning the marketing communications strategy of car dealerships, namely, the category of target audience, competition dynamic in the market environment and economical, technological and seasonal factors within the macro-environment. The findings related to macroenvironmental are presented in next sub-sections with participants' quotations.

6.1. Macro-environmental factors. The external environmental analyzis as one of the important themes pointed out by participants. The external environmental analyzis involves the scanning of variables outside the company. The external environmental analyzis includes macro-environmental analyzis and market environmental analyzis. The macro-environment analyzis involves the scanning of the following external environmental factors, just to mention the few that are pertinent in developing marketing communications, namely: economic factors, social factors, and technological factors. These external factors are analyzed to establish, which possible opportunities or threats may arise from them and impact on a marketing communication strategy. In this section, the macro-environmental variables pointed out by the participants are discussed and interpreted. The external environmental analyzis includes the scanning of the market environment which will be explored further in the next sub-section.

6.1.1. Economic factors. A few participants indicated that their dealerships consider economic factors, when developing marketing communication campaigns. Participant 2 emphasized that interest rates are major considerations when developing marketing communication campaigns in his dealership. He said:
"I think the interest rates are a talking point at the moment, so we would go and advertise interest rate, where you subsidise the interest rate".(P2)

Participant 2 added that these interest rates influence, how they structure the marketing communication messages in his dealership when planning marketing communication campaigns and they also subsidise the interest rate. He said:

"we're currently advertising interest rates because its hype at the moment." (P2)

Participant's 2 view on the consideration of interest rates was also shared by Participant 1. Participant 1 said:

\section{"we are advertising prime interest rate minus 4\%."}

According to Participants 1 and 2, interest rates are important considerations, as they are incorporated in the marketing communication messages, when developing marketing communication campaigns.

Participant 2 added that changes in fuel prices also influence the planning of marketing communication campaigns. He said:

"When fuel price goes up, it's just come down now - then and obviously we would market our vehicles, which are so fuel efficient to the rest of the competitors so you're constantly changing." (P2)

According to Participant 2, changes in fuel prices are also important considerations, as they impact on how to structure marketing communication messages, and which cars should be part of the marketing communication campaign.

6.1.2. Technological factors. The participants further pointed out that new technological advances have brought changes into customers' lifestyles in terms of media usage trends, which have also impacted on the use of marketing communication tools. The impacts of these technological changes are considered by dealerships in planning marketing communication campaigns, since the mind-set of the customer has changed. Participant 3 indicated that the dealership still generally uses traditional media types, however, they are moving towards a higher use of the internet and minimizing the usage of paper based communication methods. Participant 3 said:

"We use different types of mediums, but we're big on online which is your Auto Trader, because the world has moved now. We don't focus on magazine and newspapers that much." (P3).

According to this participant his dealership is more online due to changes in world technology and do not focus on print media, such as newspapers and magazines. 
Participant 2 added that technological innovation, specifically the internet, makes customers' lives easier and they can easily sit in their homes and together with all the decision-makers (in the family) view cars on offer in order to facilitate a buying decision. He said:

"With the internet it's made it so much easier for a buyer, where he can sit in the comfort of his home and together with all the decision-makers, the family, the wife and the kids or whatever, and look at various vehicles from the comfort of their lounge or whatever it might be. So obviously the things have shifted, the marketing activity has shifted to internet and social media."(P2)

According to Participant 2, changes in technology, specifically the internet, is an important consideration when planning campaigns, as it allows the whole family to participate in the online search for vehicles in their own spaces, and the marketing activity has shifted to internet and social media.

Participant 7 also added that changes in technology influence their decision to use the internet in their marketing communication campaigns, as it is faster than other communication platforms and user friendly. He said:

"The technology has taken over. Everybody wants to find an easier and better and faster way to do things, and the one way is to go either online. It's faster, easier, environmentally friendly, and much quicker than to buy a newspaper and page through the thing to get what you're looking for, whereas online you can just go and search it." (P7)

According to Participant 7, the technology has taken over traditional media platforms and the majority of target audiences want to find an easier and better way to search for product offerings such as vehicles online.

6.1.3. Additional external influencing factor: Seasonal factors. In addition to the mentioned macro-environmental variables mentioned at the beginning of this section, Participant 9 identified seasonal factors as an important consideration in the planning of marketing communication campaigns of his dealership. Participant 9 alluded to the fact that the allocation of budgets on marketing communication campaigns is linked to specific time periods with the busiest months of the year for getting more budget allocations. Participant 9 said:

"...then we have to sit down and say, which are the busiest months, and allocate more budget to those months..." (P9)

According to Participant 9, the annual marketing communication budget is divided up, so that the busiest months of the year get more budget allocation which illustrates seasonal considerations. In the next sub-section the findings regarding the macro-environmental factors, which are considered by car dealerships during planning of marketing communication strategies and campaigns are provided.

6.2. Market environmental factors. The market environmental analyzis involves the scanning of market variables with special attention to target audiences and competitors. In this section, the findings regarding market factors considered during external environmental analyzis are presented.

6.2.1. Target audience. In developing marketing communication strategies and campaigns, dealerships tend to follow the customer-centricity approach. It is important for marketers of car dealerships to stand out from all the media clutter and find their niche. In order to do this, marketers must identify and segment the market by defining target audiences that share similar preferences. In defining the target audiences, the dealerships use different communication methods, depending on whether the target audiences are existing customers or new customers. Defining the target audiences appropriately allows marketers of car dealerships to reach the appropriate target audiences with their marketing campaigns. The participants highlighted that the dealerships consider the target audiences' profiles, locations, and media usage trends, when planning marketing communication campaigns in efforts to ensure that the marketing messages reach the target audiences. Furthermore, the participants pointed out that customer relationship systems (CRMs) are used to capture target audiences' contact details, which are then used in marketing communication campaigns.

6.2.2. Media usage trends of existing and potential target audience. In analyzing target audiences in the market environment, Participant 10 indicated that the shift in media usage by target audiences, both existing and potential customers, guides their dealerships in terms of which media platform they should use in order to convey the marketing messages. He said:

"It moves with the trend. I mean if Facebook dies, something else will be new. We've got to keep in touch with what our customers are using as a medium of communication. If they're trending more on Twitter, we'll be on Twitter, if they're trending more on MXIT, no problem, we go back to MXIT, depending what the platforms offer for our customers, whether we can reach them an appeal to them." (P10) 
Participant 10 emphasized that their dealership keeps on monitoring target audiences' media usage trends in order to use the media platforms that will ensure that the target audiences receive the marketing communication message.

In addition to Participant's 10 view, Participant 4 pointed out that the availability of target audiences at specific places, such as shopping malls, has a bearing on the planning of marketing communication strategies and campaigns in terms of when the shopping mall displays should be carried out. He said:

"Exactly, like if you have a newer model we take it to the mall. We target those days which we know that are busy, month ends, the $15^{\text {th }}$. You know, most government departments get paid on the $15^{\text {th }}$. So there's a lot of movement at the malls, and then that's how we do it mostly." (P4)

According to Participant 4, the timing of when to engage in a particular marketing communication campaign is important to ensure the maximum exposure for the dealership's products to the target audiences.

Participant 2 added that the media usage of target audiences has changed, and their target audiences are no longer relying on traditional media platforms, such as newspapers, to search for cars, but rather these customers tend to use the internet. He said:

"Because it's actually been proven that the mind-set of the customer is changing. The customer is no longer reading through the newspaper to find his car. He is going into Google and say "find me a car". So we've experienced that a lot of customers we don't seem to have as much showroom traffic as we used to. People don't come in to have a look." (P2)

According to Participant 2, fewer customers visit their dealership's showrooms when compared to the past, due to shifts in the target audiences' media usage and mentality.

Participant 3 added that the radio station and radio shows that are mostly listened to by target audiences are selected in planning marketing communication strategies and campaigns in order to get more reach. He said:

"The target market, yes, with radio it's more influenced by the target market, because what basically happens is that the radio will tell us there are certain type of listeners and they'll give us the stats, the number of listeners, which show sells more, has more listeners and stuff like that, so we pick and choose based on the shows, because certain shows are more expensive to advertise on over certain shows, and then we do look at that, the volume versus opportunity cost, on which show presents more opportunity costs for us than the other." (P3)

According to Participant 3, certain shows are targeted, when buying marketing communication spaces in the media, and radio shows with more listeners are selected based on listenership statistics.

6.2.3. Competition dynamics. Participants indicated that competing car dealerships represent a major factor of concern due the level of competition, and further considering the threat of substitute goods or services (motor vehicles) in the market. This threat is due to the large number of car dealerships in South Africa offering more or less similar products in terms of features and attributes. In addition, the participants pointed out that their car dealerships constantly monitor their competitors' marketing communication activities with the intention of developing marketing strategies that will be distinct and catch the target audiences' attention.

Participants indicated that competition in the car retailing sector does not only exist externally, but it exists even within the dealerships, belonging to the same dealership group. Participant 4 emphasized that price competition on cars is more prevalent in the car retail sector, and this causes car retailing to be very competitive. He said:

"I can close a deal with you on 2013 model to give you an example, selling the car for R399 000. The deal is closed, when we part ways and then 5 kilometres away from my dealership you find the very same car selling about R60000 cheaper, because this is a very competitive game." (P4)

Participant 11 added that customers are aware of this price competition, and they would typically go to different car dealerships to get a quotation on the same vehicle, which will compel competing dealerships to cut prices by offering discounted prices. He said:

"A customer would typically go there and get a quotation on a vehicle, and then they would come here and get a quotation on the same vehicle here and it becomes a situation where we, you know, where we have to look at the discount to lower it a bit, or rather push it up to give the customer more discount to get the transaction, to get the deal at the end of the day. "'(P11)

Participant 3 confirmed that customers come to dealerships with quotations from competitors, which forced his dealership to act faster in closing sales deals. He said: 
"If a customer comes and they have a quotation and you see you can beat that quote you sit them down, you make the finance, you make sure that you follow all the steps to make sure that you close the deal as fast as possible. This is a different world altogether. It's - you need to strike as fast as lightning. Sometimes you need to be faster than lightning." (P3)

In addition to the external competition that exists between competing car dealerships, Participant 5 pointed out that there is internal competition amongst internal sales staff within the dealerships competing for the same clients. He said:

"We are competing against each other and on top of that you are competing against another dealership as well. Then that dealership, within that dealership there's also sales executives competing against each other. So it's all about you as an individual, how you're going to sell the cars. What makes you different to the guy sitting next to you." (P5)

According to Participant 5, in the car retailing there is competition amongst dealerships of the same brand, and sales executives are also competing against each other within the dealerships.

\section{Conclusions and discussions}

The purpose of this research was to explore the market and macro-environmental factors of consideration by car dealerships in planning marketing communication strategies and campaigns in a real life scenario. The study revealed that economical, technological and seasonal factors were the key macro-environmental factors of consideration in planning marketing communication strategies and campaigns. The findings of this study regarding economic considerations add insight to the literature that these factors of the country such as interest rates and fuel prices are considered and incorporated in marketing communication messages of car dealerships. The findings of this study regarding technological considerations during the planning of marketing communication strategies and campaigns coincide with (Fulgoni and Lipsman, 2014; Thomas and Truong, 2010; Mangold and Faulds, 2009) that organizations can benefit from these new platforms, such as social media, as these platforms present opportunities through two-way online interactions, and that new technological changes and trends influence the planning of marketing communication strategies. New technological trends and advances are adopted by car dealerships considering their relevance to sustainable development and conservation of environment in minimizing the usage of paper based communication methods. The findings of this study regarding the use of new online communication methods by car dealerships support the results of the study by De Craecker and De Wulf (2009), which uncovered that the new communication methods and practices such as email instead of postal mail, the use of recycled materials, and waterless printing can be used to conserve resources in the environment.

The findings of this study regarding seasonal factors considerations add insight to the literature that marketers of car dealerships need to consider these factors as a reference point in planning marketing communication strategies and campaigns. This study further uncovered that target audience, their media usage trends and competition dynamics were revealed to be the key factors considered in the market environment. The findings regarding the consideration of target audiences in the planning of marketing communication campaigns concur with the relationship communication model (RCM) that media usage trends of target are of importance. The research findings of this study concerning competition among car dealerships is in line with the Caemmerer (2009, p. 535) that marketers should analyze customers behavior through market research to understand, which message contents are appealing to target audiences and to identify the appropriate marketing mix elements and the appropriate media to effectively and efficiently reach target audiences. In addition, these findings support the view that marketers need to differentiate themselves by conveying unique selling propositions in the marketing communication campaigns.

\section{Recommendations}

Based on the findings of this study presented in the preceding section, it is recommended that the dealerships should ensure that they constantly monitor external environment, particulary, economic factors, such as interest rates in the country they operate in, technological changes, specifically, target audiences' media trend usages in order to guide themselves in terms of which marketing communication elements and media types need to be used to enhance their reach and the attainment of marketing communication objectives. In addition, the dealerships should understand the target audiences' needs, so that they may match the products they offer with customers' needs, and should develop marketing communication messages that promise solutions to target audiences' needs, and ultimately trigger target audiences' responses. 
The majority of participants emphasized the need to consider target audiences in the planning of the marketing communication strategies and campaigns.

Furthermore, the dealerships should also monitor the competition closely to avoid repetition of the same marketing communication messages, and should come up with unique marketing communication messages that will differentiate the dealerships' brands. Some participants further pointed out that they often have to conduct sales promotion campaigns, such as special deals and clearance sales, in an attempt to avoid the high depreciation costs and high storage costs associated with carrying excess stock levels. Based on this revelation, therefore, it is recommended that dealerships should monitor economic factors to guide them in terms of customers' demand and the stock levels to be kept that will avoid the need for sales promotion campaigns because of excess stock and high depreciation costs. Dealerships should also consider the seasons of the year, marketing communication objectives and available marketing communication budget, when planning marketing communication campaigns in order to guide allocation of budget, and allocate more budget to busiest seasons.

\section{Directions for future research}

This study explored external factors in market and macro-environment excluding internal factors that can be of consideration in planning marketing communication strategies and campaigns of car dealerships. Therefore, it is recommended that a future study could be conducted to explore on all environmental factors including the micro, market and macro-factors of consideration in practice using a different research approach and rank each factor quantitatively. Taking into account that the focus of this study was on a single sector, it is recommended that future study could focus in other sectors of the economy, as this might yield different findings. Furthermore, a study aiming to measure the extent to which organizations use environmentally friendly communication methods involving the use of new technology is recommended.

\section{References}

1. Batra, R. and Keller, K.L. (2016). Integrating Marketing Communications: New Findings, New Lessons and New Ideas, Journal of Marketing.

2. Bosdriesz, J.R., Witvliet, M.I.,Visscher, T.L. and Kunst, A.E. (2012). The influence of the macro-environment on physical activity: a multilevel analyzis of 38 countries worldwide, International Journal of Behavioral Nutrition and Physical Activity, 9(1), p.1.

3. Buil, I., de Chernatony, L., and Martínez, E. (2013). Examining the role of advertising and sales promotions in brand equity creation, Journal of Business Research, 66(1), pp. 115-122.

4. Caemmerer, B. (2009). The planning and implementation of integrated marketing communications, Marketing Intelligence and Planning, 27(4), pp. 524-538.

5. Caluschi, C. (2013). Improving a Car Dealership's Communications through the Comunicom Direct Active Communication System, Revista de Management Comparat International, 14(3), pp. 473-480.

6. Cheong, Y., Kim, K. and Kim, H. (2013). Advertising and promotion budgeting during volatile economic conditions: Factors influencing the level of decentralization in budgeting and its relations to budget size and allocation, International Journal of Advertising, 32(1), pp. 143-162.

7. Crespo Cuaresma, J. and Stöckl, M. (2012). The Effect of Marketing Spending on Sales in the Premium Car Segment: New Evidence from Germany (No. 2012-2). University of Salzburg.

8. De Craecker, F. and De Wulf, L. (2009). Integration of Green Marketing within the Automotive Industry - A case study of four car manufacturers on the Belgian market.

9. Fulgoni, G. and Lipsman, A. (2014). Numbers, please: Digital game changers: How social media will help usher in the era of mobile and multi-platform campaign-effectiveness measurement, Journal of Advertising Research, 54(1), pp. 11-16.

10. Kiran, A.H. (2012). Technological presence: actuality and potentiality in subject constitution, Human studies, 35(1), pp. 77-93.

11. Kirtiş, A.K. and Karahan, F. (2011). To be or not to be in social media arena as the most cost-efficient marketing strategy after the global recession, Procedia-Social and Behavioral Sciences, 24, pp. 260-268.

12. Kliatchko, J.G. (2009). Revisiting the IMC construct, International Journal of Advertising, 27(1), pp. 133-160

13. Lamprecht, N. (2009). Analyzis of the motor industry development programme (MIDP) as a promotional tool for the South African automotive industry in the global automotive environment, Master's dissertation, University of South Africa, Pretoria.

14. Malhotra, N.K. (2010). Marketing research: an applied orientation. $6^{\text {th }}$ global ed. Upper Saddle River, NJ: Pearson.

15. Mangold, W.G. and Faulds, D.J. (2009). Social media: The new hybrid element of the promotion mix, Business horizons, 52(4), pp. 357-365.

16. Retail Motor Industry. (2014). Members. Available at: http://www.rmi.org.za/. Accessed on 2014-02-20. 
17. Thomas L.M. (2010). Sending marketing messages within social networking, Journal Of Internet Law, July: 3-4.

18. Rollins, M., Nickell, D., and Ennis, J. (2014). The impact of economic downturns on marketing, Journal of Business Research, 67(1), pp. 2727-2731.

19. Shearman, S. (2011). Proving social media's ROI, Haymarket Business Publications Ltd, London.

20. Singh, S., Sharma, G.D., and Mahendru, M. (2011). The jugaad technology (indigenous innovations) (A case study of indian origin), Asia Pacific Journal of Research in Business Management, 2(4).

21. Tustin, Ligthelm, Martins and Van Wyk. (2005). Marketing research in practice, $1^{\text {st }}$ ed. South Africa, University of South Africa: Unisa Press.

22. Van Schie, W. (2012). The proposed short term marketing strategy for Audi South Africa focusing on distribution and after sales (Doctoral thesis).

23. Varadarajan, R. (2011). Marketing strategy: discerning the relative influence of product and firm characteristics, AMS review, 1(1), pp. 32-43.

24. Wu, J. and Olk, P. (2014). Technological advantage, alliances with customers, local knowledge and competitor identification, Journal of Business Research.

25. Zhou, T. (2011). Understanding online community user participation: a social influence perspective, Internet Research, 21(1), pp. 67-81. 